\title{
Anatomical knowledge among Medical, Dental and Health Science Professionals
}

\author{
Authors \\ Htar Htar Aung ${ }^{1^{*}}$, Htet Htet ${ }^{2}$, Goh Pui San ${ }^{3}$, Stephanie Choo Cui Fen ${ }^{4}$ \\ ${ }^{1}$ Department of Human Biology, School of Medicine, International Medical University Malaysia \\ Email: HtarHtarAung@imu.edu.my \\ ${ }^{2}$ Department of Pathology, School of Medicine, International Medical University Malaysia \\ Email: HtetHtet@imu.edu.my \\ ${ }^{3}$ Semester 8, Chiropractic Program, International Medical University Malaysia \\ Email: julie_goh94@hotmail.com \\ ${ }^{4}$ Semester 8, Chiropractic Program, International Medical University Malaysia \\ Email: stefichoo@gmail.com \\ *Corresponding Author \\ Htar Htar Aung \\ Department of Human Biology, School of Medicine, International, Medical University, Malaysia \\ No. 126, Jalan Jalil Perkasa 19, Bukit Jalil 57000 Kuala Lumpur, Malaysia \\ Email: HtarHtarAung@imu.edu.my, Tel: +60 327317509
}

\begin{abstract}
The discipline of anatomy is an integral part of curriculum for Medical, Dental and Health Sciences programs. The evolution in undergraduate medical school curricula has significantly impacted the anatomy education. The application of anatomical knowledge plays a crucial role in daily clinical practice. This review was aimed to evaluate the anatomical knowledge among the medical, dental and health science professionals, and their perceptions on application of anatomical knowledge in clinical practice. A computerized literature search which includes PubMed, Web of knowledge and Ovid Medline, was performed. The studies in the English language and published in year 2000 onwards were included. Most of the studies were done in UK and Spain followed by Australia, US and Canada. The studies conducted among Medical and Chiropractic professions were 50\% and $14 \%$ respectively. The rest of the studies were done among dentistry, podiatry, physiotherapy, radiographer and nursing students. The students with preclinical exposure scored significantly higher than those without preclinical exposure. The medical students and clinical educators perceived that the application of anatomical knowledge is not strong enough for clinical practice. The virtual medical museum, case-based learning, peer-assisted learning, inter-professional forum and the recapitulation of anatomy in clinical years are suggested to improve in anatomy education. The curriculum design, early clinical exposure, revision of course content, adequacy of learning resources and assessment methods contribute to enhance the students' learning and their ability to apply the anatomical knowledge in daily practice.

Keywords: Anatomical knowledge, application, Medical, Dental, Health Science Professionals.
\end{abstract}




\section{Introduction}

The discipline of Anatomy is an integral part of the curriculum for Medical, Dental and Health Sciences program. In the recent decades, anatomy teaching in many countries has undergone major reform in pedagogy. The application and the retention of anatomical knowledge play a crucial role in daily clinical practice; physical examination, interpretation of images and therapeutic procedures. ${ }^{(1)}$ Although anatomy is one of the fundamentals of medical curriculum, there is a decline in terms of time and resources allocated for anatomy. ${ }^{(2)} \mathrm{New}$ and innovative teaching methods of anatomy should be introduced to deliver the best possible outcome within the allocated time frame. ${ }^{(3)}$ The sound knowledge of anatomy is also important for allied health professionals. For instance, the one of the board accreditation standards for Council of Chiropractic education Australia is basic science subjects including anatomy. ${ }^{(4)}$ In the chiropractic practice, anatomical knowledge is obviously associated with the ability of performance in the clinics. ${ }^{(5)}$ Because of the awareness, European Higher Education Area has developed and implemented a paradigm shift as an integration. Health science subjects including anatomy are integrated with clinical skills for better clinical reasoning. ${ }^{(6)}$ Retention of anatomical knowledge is not only to be pointed for and the preparation from the educators' aspectis also needed to be updated in such a way that the contents and mode of delivery should meet the needs of a modern medical and health science professional world. ${ }^{(7)}$ Thus, this review was aimed to evaluate the anatomical knowledge among the medical, dental and health science professionals and their perceptions on application of anatomical knowledge in clinical practice.

\section{Materials and Methods}

A computerized literature search, which includes PubMed, Web of knowledge and Ovid Medline, was performed using the following keywords "anatomical knowledge" and "application". The studies in the English language and published in year 2000 onwards that addressed the anatomical knowledge and its application among medical, dental and health sciences programs were included. Fourteen literatures were reviewed in this study.

\section{Anatomical knowledge among house officers, medical and dental students}

The studies conducted on the anatomical knowledge among the medical students were 5 while for the dental student was only one (Table 1). Spielmann and Oliver ${ }^{(8)}$ revealed that the overall scores of the retention of anatomical knowledge on the carpal bones of the medical students were lower than that of the senior house officers. The most of graduating medicalstudents couldn't pass the multiple choice questions of a first year exam in the basic neurosciences. ${ }^{(9)}$ According to McKeow et al. ${ }^{(10)}$, the score on the surface anatomy of the medical students who were exposed to the old curriculum was higher than those who undertook the system based curriculum. Therefore, the effectiveness of learning anatomy in traditional and integrated curricula still remains a debate. In terms of radiographic anatomical knowledge, the $4^{\text {th }}$ year medical students have poor retention of specific anatomical knowledge. ${ }^{(11)}$ In the similar study by Majid D et al., the clinical students with preclinical exposure scored significantly higher than the students without preclinical exposure in chest radiographic anatomy. ${ }^{(12)}$ In the study of application of anatomical knowledge by the final year dental students of integrated curriculum, an hour test was conducted to assess the students' application of anatomical knowledge that had been learnt in the second year. The test included the questions of One Best Answer (OBA) and Objective Structured Practical Examination (OSPE). The performance of the students was weak in OSPE and the psychomotor skills of the students weren't strong enough to apply the anatomical knowledge in the clinical practice. $^{(13)}$ 
Anatomical knowledge among health sciences students

Table 1 summarized the studies conducted on the anatomical knowledge among health sciences students. A study on the preliminary assessment of the fifth-year chiropractic students' knowledge of anatomy on the carpal bone was done by Strkalj et al. ${ }^{(14)}$ It revealed that the scores of the chiropractic students were generally good because of the high number of hours dedicated in anatomy curriculum. In addition, a cross-sectional study on the retention of anatomical knowledge among preclinical (second-year) and clinical (fifth-year) chiropractic students showed that the fifth-year students performed better than the second-year students. ${ }^{(5)}$ Castillo-López et al. ${ }^{(6)}$ conducted a study using the tarsal bone test among the podiatry students and the most of the students identified the bones correctly. There was no significant difference in performance of the first and fourth-year students. Another cross-sectional study on the anatomical knowledge of upper and lower limbs was done among medical, physiotherapy, nursing, and podiatry students. The scores of the physiotherapy and podiatry students were higher than those of medical and nursing students. It was statistically significant $(\mathrm{p}<0.001)$.
In the Physiotherapy program, the anatomy discipline includes a high specificity of musculoskeletal system in their curriculum. Moreover, the different manual therapy techniques of mobilization of specific bones helped the physiotherapy students get the high score. On the other hand, the medical students from this study had not been to any clinical placements yet. ${ }^{(15)}$ Valenza et al. ${ }^{(16)}$ has concluded a study comparing the retention of anatomical knowledge on the carpal bone between third-year physical therapyand medical students at Universidad de Granada. It revealed that physical therapy students had portrayed better anatomy retention of the carpal bones than the medical students, and it was statistically significant $(\mathrm{p}<0.001)$.In the study by Hall and Durward ${ }^{(17)}$, Multiple Choice Question, short-response answers and Practical Radiographic Anatomy Examination (PRAE) were conducted among the student radiographers, and the test was repeated 10-22 months later without any announcement. Their scores were only different in PRAE and it depends on the method of assessment and period of time that had elapsed. It is encouraged that various learning and assessment plans are embraced to nurture a profound approach for enhancement in learning.

Table. 1Studies on anatomical knowledge among health professionals

\begin{tabular}{|c|c|c|c|c|c|}
\hline $\begin{array}{l}\text { Anatomical area of } \\
\text { study }\end{array}$ & Study Place & Participants & $\begin{array}{c}\text { Number of } \\
\text { participants (n) }\end{array}$ & $\begin{array}{c}\text { Author } \\
\text { (Reference) }\end{array}$ & $\begin{array}{l}\text { Year of } \\
\text { study }\end{array}$ \\
\hline Carpal bone & Murdoch University, UK & $2^{\text {nd }}$ and $5^{\text {th }}$ year Chiro & 91 & Meyer $\mathrm{A}^{(5)}$ & 2015 \\
\hline Tarsal bone & University of Seville, Spain & Podiatry & 254 & Castillo-López $\mathbf{J}^{(6)}$ & 2014 \\
\hline Carpal bone & University of Edinburgh, UK & $\begin{array}{c}\text { Final year medical } \\
\text { students and junior } \\
\text { doctors }\end{array}$ & 50 & $\begin{array}{l}\text { Spielman and } \\
\text { Oliver }{ }^{(8)}\end{array}$ & 2005 \\
\hline Neuroanatomy & $\begin{array}{c}\text { University of Saskatchewan, } \\
\text { Canada }\end{array}$ & Medical students & 24 & Mateen $\mathrm{FJ}^{(9)}$ & 2008 \\
\hline Surface anatomy & $\begin{array}{l}\text { Queen's University of } \\
\text { Belfast, UK }\end{array}$ & Medical students & 602 & McKeow PP ${ }^{(10)}$ & 2003 \\
\hline $\begin{array}{l}\text { Radiological anatomy } \\
\text { of the chest }\end{array}$ & $\begin{array}{c}\text { Johns Hopkins University, } \\
\text { USA }\end{array}$ & $4^{\text {th }}$ year Medical students & 194 & Feigin $\mathrm{D}^{(11)}$ & 2002 \\
\hline Head and Neck & Private University, Malaysia & Final year dental students & 58 & HtarHtar Aung ${ }^{(13)}$ & 2016 \\
\hline Carpal bone & $\begin{array}{c}\text { Macquarie University, } \\
\text { Australia }\end{array}$ & $5^{\text {th }}$ year Chiro & 84 & Strkalj $\mathrm{G}^{(14)}$ & 2011 \\
\hline Carpal and tarsal & University of Seville, Spain & $\begin{array}{l}\text { Medicine, Physiotherapy, } \\
\text { Nursing and Podiatry }\end{array}$ & 177 & Diaz-Mancha $\mathbf{J}^{(15)}$ & 2016 \\
\hline Carpal bone & $\begin{array}{l}\text { Universidad de Granada, } \\
\text { Spain }\end{array}$ & $\begin{array}{l}\text { Physical therapy and } \\
\text { medical }\end{array}$ & 134 & Valenza $\mathrm{MC}^{(16)}$ & 2012 \\
\hline Radiography & $\begin{array}{l}\text { Glasgow Caledonian } \\
\text { University, UK }\end{array}$ & Radiographers & 51 & $\begin{array}{c}\text { Hall A and } \\
\text { Durward } \mathrm{B}^{(17)}\end{array}$ & 2009 \\
\hline
\end{tabular}




\section{JMSCR Vol||05||Issue||11||Page 30112-30118||November}

\section{Perceptions on application of anatomical knowledge}

Vorstenbosch et al. ${ }^{(18)}$ conducted a research to determine the application of anatomical knowledge by medical doctors in an attempt to delineate the nature of competency in anatomy. It revealed that the junior medical doctors applied anatomical knowledge throughout the consultation primarily during physical examination in a patient presenting with a shoulder complaint. Lazarus MD et al. ${ }^{(19)}$ revealed that the medical students and clinical educators perceived as insufficient application of anatomical knowledge in the clinics, and the advanced anatomy course developed by clinicians and academic anatomists is essential in medical students' clinical education.In terms of the importance of anatomy topics, physicians perceived that medical imaging is highly relevant for clinical practice. On the other hand, they scored lowest for embryology and lymphatic system. ${ }^{(20)}$ Both the final year dental students and the lecturers slightly agreed that the application of knowledge was strong in radiological anatomy. Similarly, they also rated the median score for the confidence in applying anatomical knowledge during clinical practice and the adequacy of the level of knowledge on clinically relevant anatomy. ${ }^{(13)}$

\section{Approaches for improvement in Anatomy} education

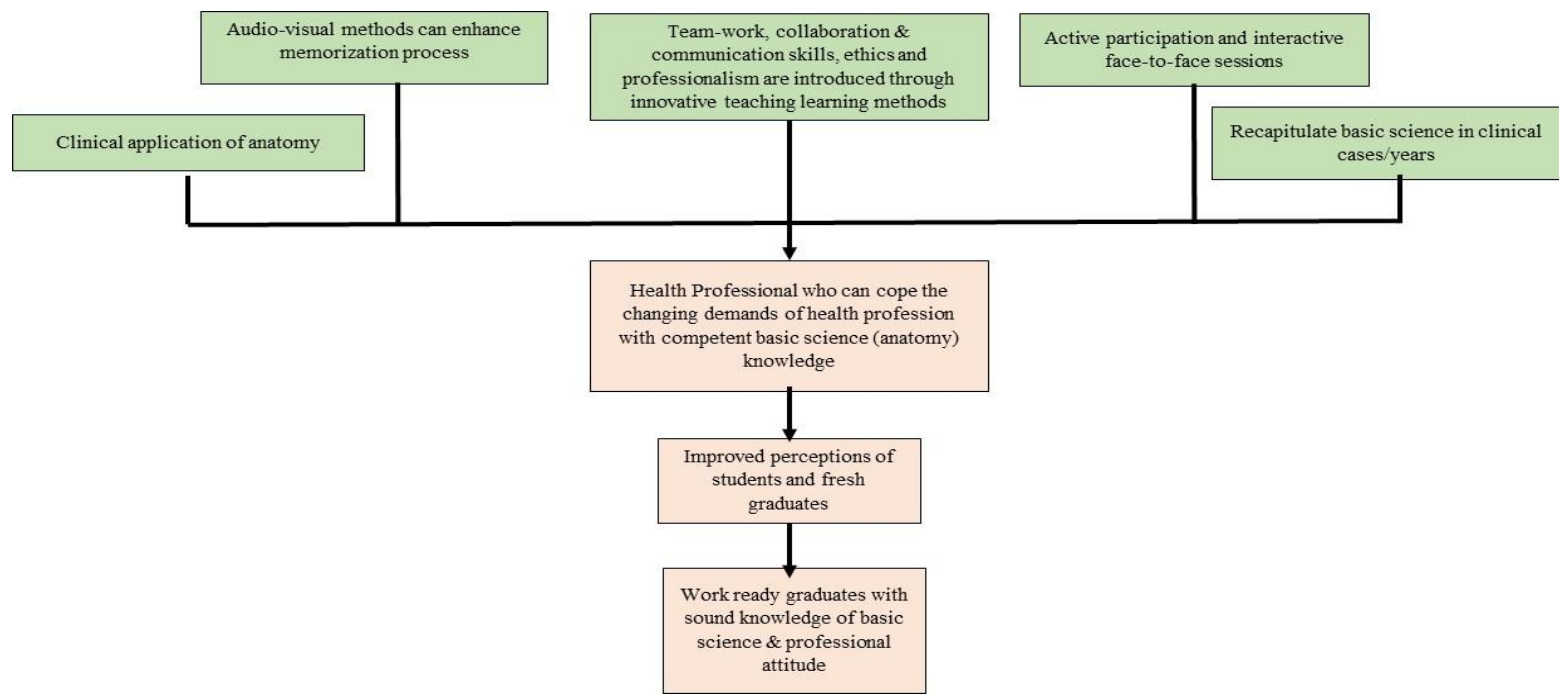

Fig. 1 Educational strategies for nurturing work-ready graduates of health professionals through learning anatomy 


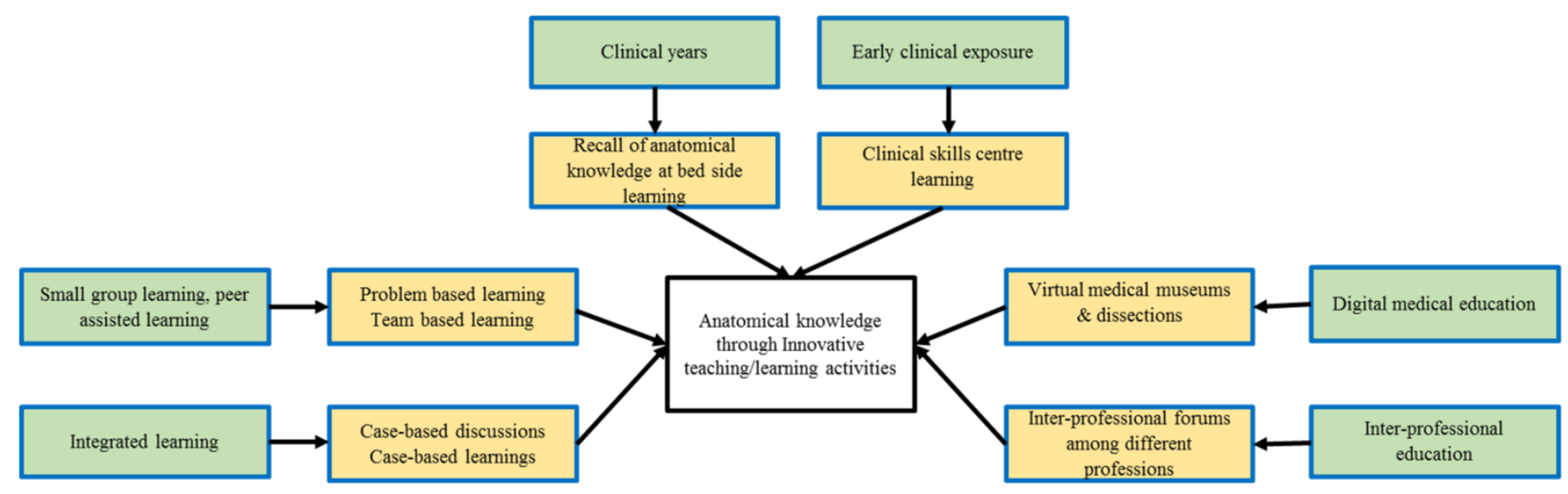

Fig. 2 Approaches for improvement in anatomy education

Based on these previous findings, the teaching/learning strategies of anatomy need to be improved in order to produce the work readiness health professionals who can cope the changing demand of health profession with competent basic science knowledge. It includes the virtual medical museum, encouragement of active students' participation, more interactive face to face sessions, case-based learning, interprofessional forum, recapitulation of anatomical knowledge in clinical years and usage of audiovisual methods (Fig 1).

The diagrammatic presentation of suggestive approaches for improvement in anatomy education was summarized in Figure 2.

\section{Conclusion}

The curriculum design, early clinical exposure, revision of course content, adequacy of learning resources, perceptions of the students and educators, the assessment methods contribute to enhance the learning gross anatomy in health professionals and its application in daily clinical practice.

\section{References}

1. Arráez-Aybar L, Sánchez-Montesinos I, Mirapeix R, Mompeo-Corredera B, Sañudo-Tejero J: Relevance of human anatomy in daily clinical practice. Annals Of Anatomy - Anatomischer Anzeiger 2010; 192(6): 341-348. doi: 10.1016/j.anat.2010.05.002.

2. Gogalniceanu P, Madani H, Paraskeva PA, Darzi A: A minimally invasive approach to undergraduate anatomy teaching. Anat Sci Educ. 2008; 1(1):46-7. doi: 10.1002/ase.9.

3. Craig S, Tait N, Boers D, McAndrew D: Review of anatomy education in Australian and New Zealand medical schools. ANZ J Surg. 2010;80(4):212-6. doi: 10.1111/j.1445-2197.2010.05241.x.

4. Chapman PD, Meyer A, Young K, Wibowo D, Walker B: Emphasis on various subtopics in the anatomy curriculum for chiropractic training: An international survey of chiropractors and anatomists. J Chiro Educ 2015;29(1). dOI 10.7899/JCE-14-10.

5. Meyer A, Armson, A, Losco C, Losco B, Walker B: Factors influencing student performance on the carpal bone test as a preliminary evaluation of anatomical knowledge retention. Anatomical Sciences Education. 2015;8(2): 133-139.

6. Castillo-López J, Díaz-Mancha J, HerediaRizo A, Fernández-Seguín L, Polo-Padillo J, Domínguez-Maldonado G, Munuera P: 
The Tarsal Bone Test: A Basic Test of Health Sciences Students' Knowledge of Lower Limb Anatomy. Biomed Research International2014;1-6.

doi: 10.1155/2014/939163.

7. Sbayeh AA, Choo MAO, Quane KA, Finucane P, McGrath D et al: Relevance of anatomy to medical education and clinical practice:perspectives of medical students, clinicians, and educators. PerspectMed Educ 2016; 5:338-346. dOI 10.1007/s40037-016-0310-4.

8. Spielmann, P. \& Oliver, C: The carpal bones: A basic test of medical students' and junior doctors' knowledge of anatomy. The Surgeon.2005; 3(4): 257-259.

9. Mateen FJ, D'Eon MF: Neuroanatomy: A single institution study of knowledge loss. Med Teach.2008; 30(5), 537-539.

10. McKeow PP, Heylings DJA, Stevenson M, McKelvey KJ, Nixon JR, McCluskey $\mathrm{DR}:$ The impact of curricular change on medical student's knowledge of anatomy. MedEduc. 2003;37(11): 954-961.

11. Feigin, D, Smirniotopoulos J, Neher T: Retention of Radiographic Anatomy of the Chest by 4th-Year Medical Students. J Academic Radiology. 2002;9(1): 82-88. doi: 10.1016/S1076-6332(03)80299-4.

12. Magid D, Hudson DW, Feigin DS: Chest Radiographic Anatomy Retention. The impact of preclinical groundwork on clinical recall in two schools. $\mathrm{J}$ Academic Radiology 2009; 16(11): 1443-47. doi: 10.1016/j.acra.2009.07.012.

13. HtarHtar Aung, AnkurBarua, Anupa Sivakumar, Khin Ma Ma: Application of anatomical knowledge by final year dental students of integrated curriculum: A pilot study. JMSCR. 2016; 4(11): 13827-33.

14. Strkalj G, Schroder T, Pather N, Solyali V: A Preliminary Assessment of the FifthYearChiropractic Students' Knowledge of Anatomy. J Altern Complement Med.
2011

17(1):

63-66.doi:

10.1089/acm.2010.0157.

15. Díaz-Mancha J, Castillo-López J, Munuera-Martinez P, Fernández-Seguín L, Polo-Padillo J, Heredia-Rizo A: A Comparison of Fourth-Year Health Sciences Students' Knowledge of Gross Lower and Upper Limb Anatomy: A Cross-Sectional Study. Journal Of Manipulative And Physiological Therapeutics. 2016;39(6): 450-457. doi: 10.1016/j.jmpt.2016.05.007.

16. ValenzaMC, Castro-Martín E, Valenza G, Guirao-Piñeiro M, De-la-Llave-Rincón A, Fernández-de-las-Peñas $\mathrm{C}$ : Comparison of Third-Year Medical and Physical Therapy Students' Knowledge of Anatomy Using The Carpal Bone Test. Journal Of Manipulative And Physiological Therapeutics. 2012;35(2): 121-126. doi: 10.1016/j.jmpt.2011.12.005.

17. Hall A, Durward B: Retention of anatomy knowledge by student radiographers. Radiography 2009;15(3): 22-28. doi: 10.1016/j.radi.2009.03.002.

18. Vorstenbosch M, Kooloos J, Bolhuis S, Laan R: An investigation of anatomical competence in junior medical doctors. Anatomical Sciences Education. 2015;9(1): 8-17.

19. Lazarus M, Chinchilli V, Leong S, Kauffman G: Perceptions of anatomy: Critical components in the clinical setting. Anatomical Sciences Education. 2012;5(4): 187-199.

20. Orsbon CP, Kaiser RS, Ross CF: Physician opinions about an anatomy core curriculum: A case for medical imaging and vertical integration. Anatomical Sciences Education. 2014; 7(4): 251-261.

21. Spampinato CM, Wittich CM, Beckman TJ, Cha SS, Pawlina W. 'Safe Harbor': Evaluation of a professionalism case discussion intervention for the gross 
anatomy course. Anat Sci Educ. 2014;7: 191-8.

22. L. J. Rizzolo, W. B. Stewart: "Should we continue teaching anatomy by dissection when...?" Anatomical Record. Part B, New Anatomist. 2006; 289(6): 215-218. 